\title{
Asymmetrical bargaining in the conference on security and cooperation in Europe
}

\author{
P. Terrence Hopmann
}

\begin{abstract}
Bargaining relationships in formal international conferences and negotiations may involve structural asymmetries. A comprehensive analysis of these asymmetries in bargaining may be found in a synthesis of literature from formal game theory, structural-manipulative approaches to bargaining, social psychology, and the study of political influence. Propositions based on this literature focus on two factors which are likely to contribute to asymmetrical outcomes in negotiations: unequal costs to the negotiators from the failure to agree, and unequal resources available to employ in bargaining or influence attempts. An analysis of bargaining in the section of the Conference on Security and Cooperation in Europe (CSCE) dealing with the issues of European security gave qualified support to these propositions. Influence over the final text in the CSCE agreement is related to a rough index of losses which would have resulted for individual nations from the failure to reach agreement in the CSCE. In addition, influence over the final text is related to each nation's resources, especially military resources. More significantly, the two superpowers exerted considerable asymmetrical influence over what was not included in the CSCE agreement, thus exercising a substantial veto. Thus, the asymmetrical outcomes within the CSCE negotiations were reflective of both differences in "threat potential," that is, in the losses which actors would receive if no agreement had ensued, as well as differences in resources.
\end{abstract}

P. Terrence Hopmann is Director of the Center of International Studies and an Associate Professor of Political Science at the University of Minnesota. Interviews upon which the research reported in this paper was based were undertaken in part while the author was a research fellow under the Fulbright-Hays Act in Belgium during 1975-76. Additional interviews were undertaken in Geneva, Switzerland in 1974, with the cooperation of the European Centre of the Carnegie Endowment for International Peace, especially of John Goormaghtigh and Jean Siotis. The author is also indebted to the Office of International Programs at the University of Minnesota for financial support for research and travel in Geneva in 1974. Finally, he would like to express his gratitude to Timothy King and Charles Walcott for their contributions to the development of the theory presented in this paper and to James Caporaso, Raymond Duvall, and Brian Job for their helpful comments on an earlier draft of this paper. 


\section{Introduction}

Asymmetries in international relations may be manifested in many different ways. This paper will focus upon some of the asymmetries which may appear in the course of bargaining among nations in a relatively formal conference setting. Although the process of international negotiation has received increased attention in the literature of international relations in recent years, relatively little of that attention has been directed towards the issue of inequality and asymmetry within the bargaining process. Therefore, one must look largely outside the field of international relations in search of heuristic propositions which might guide research in this area. This paper will review a wide range of literature, including formal game theory and theories of strategy and bargaining, in the search for propositions that might help to explain the conditions under which negotiations will produce asymmetrical outcomes.

Propositions which are developed in this fashion may be of value in guiding research, although they are unlikely to produce any definitive answers to questions about the bargaining process. The validity of these propositions may be evaluated according to two principal standards. The first standard is a logical one: whether or not the propositions can be justified on the basis of consistency with some fundamental assumptions and rules of interrelatedness. This paper will attempt to synthesize a model of the bargaining process with special reference to the issue of asymmetrical outcomes. The primary purpose of this will not be to derive nonobvious propositions from a formal theory, although this approach may fortuitously produce such results on occasion. Rather the principal objective here will be simply to evaluate the logical foundations of some basic propositions about asymmetries in the bargaining process, applying the test of logical consistency. Of course, propositions may be logically consistent but still not valid for describing or explaining a process occurring in international relations. Therefore, the second test for the validity of the propositions is an empirical one; whether or not the propositions are consistent with observed data. Therefore, the paper will explore the empirical plausibility of the propositions developed here through a case study consisting of an analysis of that portion of the negotiations in the Conference on Security and Cooperation in Europe (CSCE) which dealt with the issues of security and with "confidence building measures."

There has been considerable attention in recent international relations research to the issue of international negotiations, with the most important work probably being that of Iklé ${ }^{1}$ and Lall. ${ }^{2}$ Most of these approaches to negotiations have focused on a set of interdependent actors engaged in bargaining, although surprisingly little attention has been devoted to the "asymmetrical interdependencies" which may

\footnotetext{
${ }^{1}$ Fred Charles lklé, How Nations Negotiate (New York: Praeger, 1964).

${ }^{2}$ Arthur Lall, Modern International Negotiations (New York: Columbia University Press, 1966).
} 
exist among the participants. ${ }^{3}$ Most attention has been devoted to studies of Soviet-American negotiations on issues such as the Partial Test Ban Treaty and the Strategic Arms Limitations Talks, where such asymmetries have largely not been present. Much of the literature has overlooked the fact that power resources and control relations among the actors engaging in many international negotiations are not even approximately equal. This applies within the major power alliances, where the superpowers and the smaller bloc members certainly do not have equal bases to provide resources to "affect other actors" directly, to deprive them of "desired exchange goods," or prevent one another from "achieving domestic goals." 4 This also applies to the relations between nonaligned actors, especially the less developed countries of the world on the one hand, and members of the two superpower blocs, on the other.

Power discrepancies have not been totally overlooked in recent writing on negotiations. For example, Lall has suggested the following proposition about the relationship between power asymmetry and the negotiation process:

When there is a real or assumed significant disparity of power between the parties to a dispute or situation, or when one of the parties is imbued with a sense of growing power, then such disparity or sense of buoyant power may militate against resort to negotiation to settle the dispute or ameliorate the situation. ${ }^{5}$

While Lall emphasizes power considerations with regard to the issue of entry into negotiations and concerning a country's general stance towards negotiations, when he turns to the subject of concessions and movements towards agreement he tends to deal almost exclusively with considerations of bargaining strategy. The structural asymmetries among the actors are not introduced as a significant consideration affecting the process and outcome of negotiations. Thus a central objective of this paper is to extend theories of negotiation to include assumptions about the effects of structural asymmetry upon the bargaining process. An adequate theory of bargaining at the international level must include such a component in order to describe and explain how negotiations operate in the realm of international relations.

The concept of asymmetry as it is treated in bargaining theory is similar to theories of power, influence, or relational control as exhibited in other work in international relations, although the emphasis is sometimes different. One major difference in emphasis is that theories of bargaining assume that actors seek an end goal of agreement and that they hope to collaborate in some way to receive mutually beneficial outcomes which they cannot achieve unilaterally. As Iklé observes,

\footnotetext{
${ }^{3}$ Robert O. Keohane and Joseph S. Nye, "World Politics and the International Economic System," in C. Fred Bergsten, ed., The Future of the International Economic Order: An Agenda for Research (Lexington, Mass.: Lexington Books, 1973).

"James A. Caporaso, "Relational Control and Power in the Global System: A Structural and Behavioral Analysis" (Evanston: Northwestern University, mimeo, 1975).

${ }^{5}$ Lall, p. 150.
} 
"Two elements must normally be present for negotiations to take place: there must be both common interests and issues of conflict." 6 If there were no common interests, then there would be no basis for negotiations; in this case a theory of coercion would perhaps be more applicable. On the other hand, if there were no conflicting interests, then there would be nothing to negotiate about as the actors' positions might be expected to converge naturally. In short, bargaining theory deals with "mixed motive" situations in which the individual interests of actors are partially but not completely overlapping. By contrast, theories of dependence as relational control may deal only with unilateral relationships in which one actor may require another with completely different interests to act in a manner preferred by the former. Although most bargaining relationships are multidirectional and are based in part on common interests, concepts of influence and relational control are still relevant in many instances. The fact that two or more actors have some interests in common does not mean that they are in the same structural position to influence the negotiated outcomes; nor does it mean that a resulting agreement will benefit all actors equally. In order for an agreement to occur, all actors must perceive that they will receive a better net outcome with the agreement than they would without it. However, the overall gains may not necessarily be distributed evenly among the actors, and this unevenness in outcomes may be the result of structural or relational asymmetries among the actors. It is at this point that these two approaches meet and need to be integrated more fully.

\section{Structural asymmetry in a theory of bargaining}

In this section I shall begin to develop a framework to analyze the effects of structural asymmetry in bargaining situations. The sections will draw heavily upon the literature of formal game theory, social psychology, and political models dealing with power and influence relations to identify some tentative propositions about how structural asymmetry will affect bargaining. This review will be based largely upon theoretical developments in past work on bargaining, but it will attempt to sharpen and extend those aspects which deal most extensively with asymmetry. In this effort, I will be operating primarily at the level of "the state as actor," based upon the assumption that negotiators at international conferences serve as representatives of their states and are the articulators of policy outcomes developed within the decision-making apparatus of the state. However, in order to evaluate the effect of structural factors on bargaining, it will also be necessary to look at the systemic context within which most negotiations occur.

${ }^{6}$ Iklé, p. 2. 
The game theoretic orientation

One of the most prominent sources of models about the negotiation process is mathematical game theory. There are, of course, some serious limitations to the application of game theoretic models to the analysis of international negotiations. For example, game theoretic models assume that the number of players in a game is fixed and known, that each player acts rationally in the sense of trying to maximize his own personal gains, that payoff functions are fixed and known in advance by the players, and that communications between the players cannot affect the form or content of the game. ${ }^{7}$ Many of these assumptions are not met in international negotiations, especially the assumptions about communications and about perfect information concerning payoff functions. Furthermore, game theoretic models alone tend to be static, dealing largely with the relationship between initial conditions (actors' preferences) and outcomes (the distribution of some value). Little direct attention is paid to the dynamic process of negotiation. In spite of these very serious limitations, game theoretic models may help to clarify the structure of negotiation situations. They may also provide a foundation for building more complex and dynamic models of bargaining through the introduction of elements not included in formal game theoretic models.

\section{The bargaining game}

Most game theoretic models of bargaining are classified as two-person, nonzero-sum games. Bargaining necessarily involves a theory of non-zero-sum games, since as noted previously negotiations occur only in "mixed motive" situations in which elements of cooperation and conflict are present simultaneously. Since this paper deals with a multilateral conference, an n-person theory would appear to be more appropriate than a two-person theory. However, the treatment of the bargaining problem is currently far better developed in the two-person case and is thus heuristically more interesting. Therefore, I shall begin with a two-person model and then suggest some of the implications of expanding it to deal with the $n$-person case later in this section.

A classic two-person, non-zero-sum representation of the bargaining situation is depicted in matrix form in Figure 1. This game is generally referred to as the "Battle of the Sexes." " Unlike some games, this particular one does not have a single solution which would always be obtained in one play of the game. Rather, any long-term solution of this game must be determined through the "mixed strategies" which players would employ if they were to play this game many times. A schematic representation of this matrix is presented in Figure 2, assuming that the

\footnotetext{
${ }^{7}$ Oran R. Young, Bargaining: Formal Theories of Negotiation (Urbana, Ill.: University of Illinois Press, 1975), p. 23.

${ }^{8}$ An excellent exposition of the "Battle of the Sexes" as a basis for the game theoretic treatment of the negotiated game may be found in Anatol Rapoport, Two Person Game Theory (Ann Arbor: University of Michigan Press, 1969).
} 
Figure 1. The "Battle of the Sexes": Utility Matrix

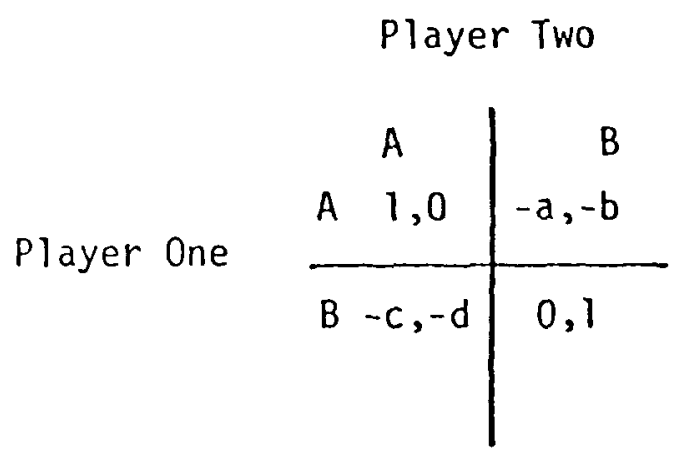

Figure 2. The "Battle of the Sexes": Payoff Polygon

Player One's Payoffs

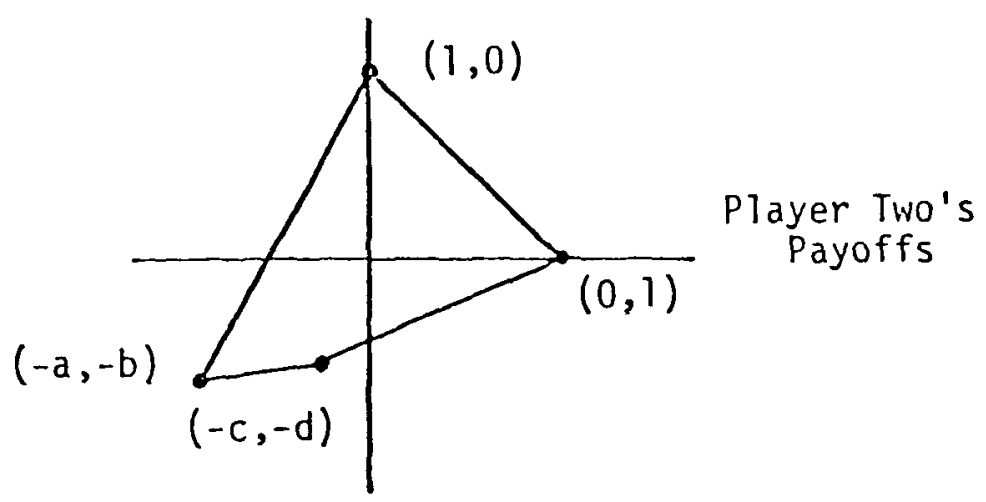


values of $a, b, c$, and $d$ are all greater than zero and less than one and that the minimum values of $a$ and $b$ are greater than the maximum values of $c$ and $d$. The polygon which connects the four possible outcomes on any one play of the game contains all possible combinations of payoffs for both players. The players could employ any combinations of mixed strategies, always producing long-term solutions somewhere inside this polygon. However, the players will not be maximizing their own utilities unless they reach an agreement within this polygon along the line connecting $(1,0)$ and $(0,1)$. Along this line one player can do better only at the expense of the other player, so this line is referred to as the negotiation set. It is along this line that tradeoffs must be made between the preferences of the two players. Thus the first assumption of the bargaining game is that agreement should be reached along a line where both of the players are no longer able to improve their payoffs jointly. The effort to reach this point in the game is essentially cooperative. However, the struggle to achieve a final solution at some point along this line tends to be largely conflictual, since movement in either direction will benefit one player at the other's expense.

In order to determine the range of acceptable agreements along the negotiation set, one must also calculate each player's minimum payoff, that is, the outcome which he can assure himself by playing alone without regard for the play of the other. This outcome is calculated by each player as if he were playing a zero-sum game and selecting his minimax strategy. No matter what the other player does, one cannot be forced into a worse outcome than that based on the minimax strategy. This minimum payoff which each actor can assure himself is known as his security level. In some instances the security levels of the players fall outside the negotiation set, in which case they in no way constrain the outcomes reached. In other cases they may serve to restrict the negotiation set as diagrammed in Figure 3. Since a player will not settle for a negotiated settlement below his security level, when these bounds do cross the negotiation set they will reduce the range of viable agreements along that set. Thus, the second essential assumption of the bargaining game is that agreement will fall on the negotiation set within the range circumscribed by the security levels of the two players, as no player will accept a negotiated settlement that would leave him worse off than he would be by acting alone.

Thus far the model of the negotiated game leaves undetermined the precise point at which an agreement will occur, and the procedure for determining this point has been the subject of some dispute among game theorists who are not in fundamental accord about what additional assumptions should be made. Yet the determination of this point is important if one wants to determine whether outcomes will be relatively equally divided between the two actors or if they will tend to favor one rather than another. Perhaps the most basic solution has been proposed by Nash, who suggests three assumptions in addition to those already stated: ${ }^{9}$

9John F. Nash, “Two Person Cooperative Games," reprinted in Young, pp. 69-71. 
Figure 3. The Restricted Negotiation Set

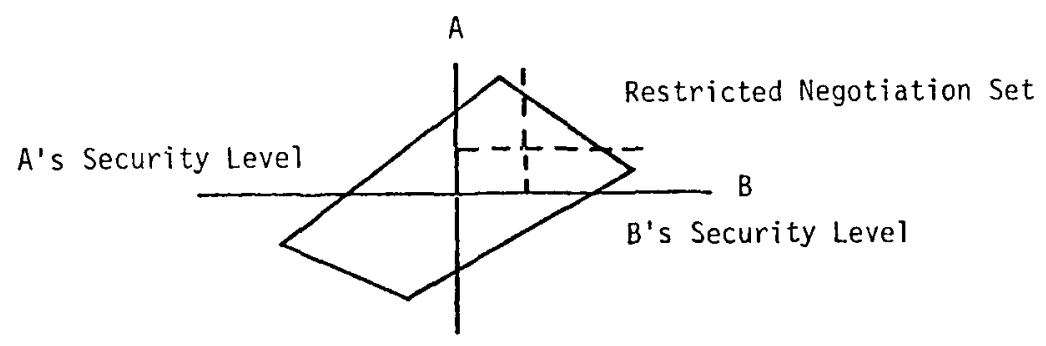

(1) The transformation invariance axiom: linear transformations of the payoffs do not change the relative position of the players with regard to the solution.

(2) The symmetry axiom: the solution does not depend on how the players are labeled.

(3) The independence of irrelevant alternatives axiom: the solution is independent of irrelevant alternatives such as would occur if additional payoff pairs became available without changing the status quo point.

Nash then demonstrates that there is one unique solution which will maximize the product of the differences between the values of the game for both players and the values of the status quo point, in this case the values which the players would receive if they didn't play the game at all. In the case of the matrix depicted in Figures 1 and 2 , the only payoffs considered in calculating the solution would be $(1,0)$ and $(0,1)$, and the solution would be for each player to get his preference 50 percent of the time. Over a series of plays the average payoff would be .5 for each player. This solution thus produces an outcome which approximates a common sense notion of "equity" or "splitting the difference." This solution applies, however, only when the status quo point is fixed and the game is symmetrical.

Other proposed solutions take account of the other values in the payoff matrix, and they treat the status quo points as variable. Thus, if the non-cooperative outcomes produced costs for the two parties which were not equal, then the status quo point would be located at a point which would produce asymmetrical outcomes for the players. There have been a number of major efforts to establish variable status 
quo points. ${ }^{10}$ One, introduced by Shapley, requires player $A$ to threaten to play $A$ 's own minimax strategy, thereby leaving $B$ worse off than he would be if $A$ pursued a cooperative strategy. ${ }^{11} \mathrm{~A}$ second, suggested by Nash, requires player $A$ to threaten to leave player $B$ at $B$ 's security level. ${ }^{12}$ In Shapley's solution, $A$ threatens to seek $A$ 's own security level, which may or may not leave $B$ at his security level, depending on the structure of the payoff matrix; however, this is certain to leave $B$ worse off than if they had reached a cooperative outcome. In Nash's solution, $A$ threatens to force $B$ to $B$ 's security level.

The calculation of these two outcomes is somewhat more complex than for Nash's simple solution. Shapley's solution requires that one take into account the values of $a, b, c$, and $d$ from Figure 1. From this a status quo point is located as the intersection of the security levels of the two players. In the determination of this status quo point, then, the losses of the players from noncooperative outcomes are taken into account and affect the outcome. If there are no differences between the losses of the two players (i.e., if $a=b$ and $c=d$ ); then the solution reduces to Nash's simple one. On the other hand, if $A$ 's losses from the failure to agree are greater than $B$ 's (i.e., if $a>b$ and $c>d$ ), then B's preferences will tend to be favored more often. In short, the player who stands to lose the most from the failure to agree will get a smaller proportion of the outcome. An inequality in losses from noncooperation can produce asymmetric outcomes even in the case where the actual agreement is obtained along the negotiation set. This is because the player who can threaten the other with a noncooperative result with the least cost to himself is in a better position to demand a greater share of the gain from a cooperative outcome. Shapley refers to this form of influence as "threat potential." The less the costs of noncooperation, the greater the potential to threaten the other party with noncooperative outcomes in an effort to extract a greater share of any potential gains. Nash's extended solution is similar to Shapley's, except that it focuses on what player $A$ can threaten to do to $B$ by leaving $B$ at his security level. It thus deals with the costs to the player if the other player chooses to punish him for failing to agree to terms favored by the first. In this case the player who would suffer the greater punishment if left at his security level has less threat potential and therefore less capability to influence the outcome of an agreement.

In short, these game theoretic models suggest that asymmetrical outcomes in negotiation will be affected by the relative threat potential of negotiators, in the following ways: (1) those actors with the least cost from noncooperative outcomes will have the greatest threat potential and are thus likely to obtain a proportionately larger share of the outcome of an agreement, whereas those actors with the greatest

\footnotetext{
${ }^{10}$ Several possible solutions not discussed here have been proposed by Howard Raiffa, "Arbitration Schemes for Generalized Two-Person Games," in H. W. Kuhn and A. W. Tucker, eds., Contributions to the Theory of Games, II (Princeton, N.J.: Princeton University Press, 1953), and R. B. Braithewaite, Theory of Games as a Tool for the Moral Philosopher (Cambridge: Cambridge University Press, 1955). "L.S. Shapley, "A Value for N-Person Games," in H.W. Kuhn and A.W. Tucker, eds., op. cit.

${ }^{12}$ John F. Nash, "Noncooperative Games," Annals of Mathematics, Vol. 54: 155-62.
} 
costs from noncooperative outcomes will have the least threat potential and are thus likely to obtain a proportionately smaller share of the outcome of an agreement; (2) those actors who will suffer the greatest loss from being left at their security levels will have the least threat potential and are thus likely to obtain a proportionately smaller share of the outcome of an agreement, whereas those actors who will suffer least from being left at their security level will have the greatest threat potential and thus are likely to obtain a larger share of the outcome of an agreement.

Thus outcomes along the negotiation set are influenced by the location of the status quo point. In proposition (1) the status quo point is determined by the intersection of the security levels of the two players. In proposition (2) it is the threat by one player to reduce the status quo point of the other to the other's security level which affects the outcome. Both propositions explain asymmetrical outcomes largely as a function of the costs to the actors of noncooperative solutions, and both tend to suggest that the player with greater costs from the failure to cooperate will receive less in any solution, including a cooperative one along the negotiation set.

The two-person model of bargaining has been extended into n-person game theory by Harsanyi. ${ }^{13}$ In this instance, instead of considering the bargaining positions of individual actors, the model looks at all possible subsets of players, called syndicates, which might potentially form coalitions. When the two maximal coalitions are found, the bargaining between them reduces essentially to that predicted by the model from two-person game theory. In the case of international negotiations, however, actors do not enter into coalitions on the basis of purely utilitarian considerations. Rather, in most instances, coalitions are preformed and are fairly stable, so that aspects of $n$-person game theory dealing with coalition formation are likely to be of relatively little interest in the case of many formal conferences (although they might be of some interest for institutions like the UN General Assembly). Without making assumptions about coalition formation, however, n-person game theory does not produce any determinate results and is thus of little heuristic value in comparison with the two-person version. Therefore, although it requires considerable simplification, interactions in this paper will be treated largely in terms of two-person bargaining between opposing coalitions or alliances or in terms of a series of bargaining dyads connecting independent actors without regard for other actors with whom they may be interacting simultaneously. ${ }^{14}$

\section{An application of the asymmetrical bargaining game to international negotiations}

I shall next attempt to extend the conceptualization based on formal game theory into a general bargaining model which will focus on some of the behavioral

\footnotetext{
${ }^{13} J o h n$ C. Harsanyi, "A Bargaining Model for the Cooperative N-Person Game," in R.D. Luce and A.W. Tucker, eds., Contributions to the Theory of Games, IV (Princeton, N.J.: Princeton University Press, 1959).

${ }^{14}$ For an extensive treatment of $n$-person game theory and of its limitations for the purposes of the present analysis see Anatol Rapoport, N-Person Game Theory (Ann Arbor: University of Michigan Press, 1970).
} 
implications of the more formal theory. Such a model may then be modified to introduce dynamic elements, including strategic and psychological considerations, which are not treated adequately in the basic model.

One implication of the formal bargaining game is that negotiations are likely to be composed of two logically separate, though not necessarily temporally separate, phases. The first phase entails the effort to seek agreements which fall within the negotiation set. In Figure 2 any solution to the lower left of the line connecting payoffs $(1,0)$ and $(0,1)$ would be contrary to the interests of both parties. Thus any potential solutions falling anywhere within the negotiation polygon other than on the negotiation set, that is, the northeast boundary of the polygon, are not optimal in the sense that each party can improve its position without necessarily hurting the other. In other words, mutually beneficial moves are possible anywhere within the polygon except on the northeast boundary. In an important work on labor negotiations, Walton and McKersie describe this aspect of negotiations as "integrative" bargaining. They define integrative bargaining as a "system of activities which is instrumental to the attainment of objectives which are not in fundamental conflict with those of the other party and which therefore can be integrated to some degree." 15 The process of integrative bargaining is characterized by "problem-solving," in which the negotiators seek to identify common interests. Thus, this phase of bargaining essentially entails cooperation between actors. A negotiation polygon which should produce a purely integrative solution to the bargaining problem is depicted in Figure 4. In this case any solution other than at point $p$ is not in the interest of either party. Thus once the two parties have identified between themselves the existence of this point, they should be able to agree upon it at once. Although there may be structural asymmetries that produce a situation like that depicted in Figure 4, there should be no asymmetry in incentive to influence or force the other to move from point $p$.

The second phase of the negotiation process, at least in a situation like that depicted in Figure 2, is a conflictual one, which Walton and McKersie characterize as requiring a "distributive" bargaining process. They refer to this as "the complex system of activities instrumental to the attainment of one party's goals when they are in basic conflict with those of the other party." 16 It is this aspect of bargaining which has attracted the greatest attention of game theorists, because it is here that the question of distributing the gains of an agreement arises. In the case of the matrix in Figure 2, the players must decide on a mixed strategy to determine what proportion of the time player $A$ wins the utility of 1 relative to the proportion when $B$ wins. It is here that their interests diverge, since each would prefer to win almost always and receive an average payoff for himself as close to 1 as possible, leaving the other with an average payoff as close to 0 as possible. It is in this phase that the asymmetrical capability to threaten enters in to the determination of this distribution.

\footnotetext{
${ }^{15}$ Richard E. Walton and Robert B. McKersie, A Behavioral Theory of Labor Negotiations (New York: McGraw-Hill, 1965), p. 5.

${ }^{16}$ Ibid., p. 4.
} 
Figure 4. A Purely Cooperative Game

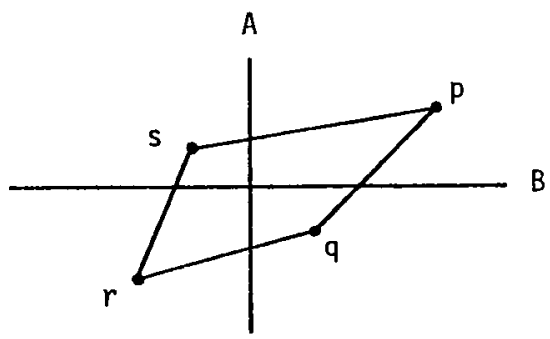

Figure 5. A Mixed Motive Game

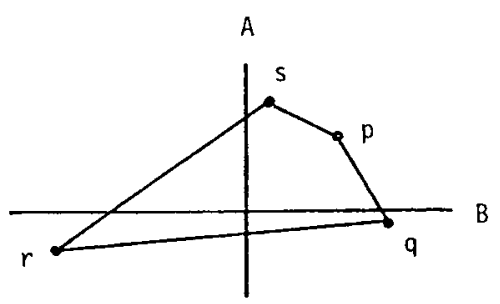


As Walton and McKersie point out, however, a purely game theoretical solution does not take into account some of the behavioral phenomena which tend to appear when individuals are forced to play games with both integrative and distributive characteristics. For example, a polygon such as that depicted in Figure 5 would lead, according to Nash's procedure, to an agreement at point $p$. However, the solution at this point is not stable, unlike at point $p$ in Figure 4, because each party still has an incentive to move away from it in a direction designed to secure for himself unilateral gains at the expense of the other. Indeed, in this case the party not moving would suffer greater losses than the other gained. Such a move, of course, violates the assumptions of Nash's theory which seeks to maximize joint payoffs and arrive at some "fair" distribution reflecting the different utility schedules of the actors. But if one actor desires more than his "fair" share, there is nothing in the logic of the game to prevent him from seeking such gain.

The arguments made thus far may be summarized by reference to a simple bargaining model, diagrammed in Figure 6 . This model depicts on a horizontal axis an issue dimension along which both parties are assumed to have conflicting preferences. In this diagram $A$ prefers outcomes towards the left, as close as possible to point $a^{\prime}$, whereas $B$ prefers outcomes towards the right as close to $b^{\prime}$ as possible. Lines $A--A^{\prime}$ and $B--B^{\prime}$ represent a utility curve in which gains and losses are standardized with reference to some status quo point such as the value of no agreement. Thus at any point along the issue dimension the expected gains and losses which each actor would receive relative to the neutral outcome of the continuation of the status quo may be located. By using a common status quo point for both players such as the value of no agreement, the preferences of the two parties may be compared with one another. This does not necessarily imply that the actors feel indifferent about the status quo in some absolute sense, but simply that their comparative gains and losses may be measured relative to some such point. The points where these utility curves cross the neutral line thus represents the security level or minimum acceptable solution for each actor, indicated by points $a$ and $b$. Thus for actor $B$ any proposed solution to the left of point $b$ would represent a net loss relative to the status quo. Since $B$ can always insure himself of at least the status quo by refusing to agree, there is no logical reason for him to accept any solution falling beyond point $b$. By the same argument $A$ would presumably refuse to accept any solutions to the right of point $a$. Thus the model makes it clear that no rational actor will accept a settlement which falls below the point of his own security level. It therefore follows that all agreements must fall within the range between the minimum acceptable positions of the two actors, and this range may be referred to as bargaining space.

The bargaining space depicted in this model produces a situation comparable to that also noted in Figure 5; that there is one point at which the products of the two individual utilities may be maximized, point $E$ in Figure 6 or point $p$, which corresponds to it, in Figure 5. Point $E$ is not necessarily located half way between either the minimum positions of two actors, points $a$ and $b$, or half way between their maximum positions, points $a^{\prime}$ and $b^{\prime}$. It is partially a function of these points 


\section{Figure 6. A Simple Bargaining Model}

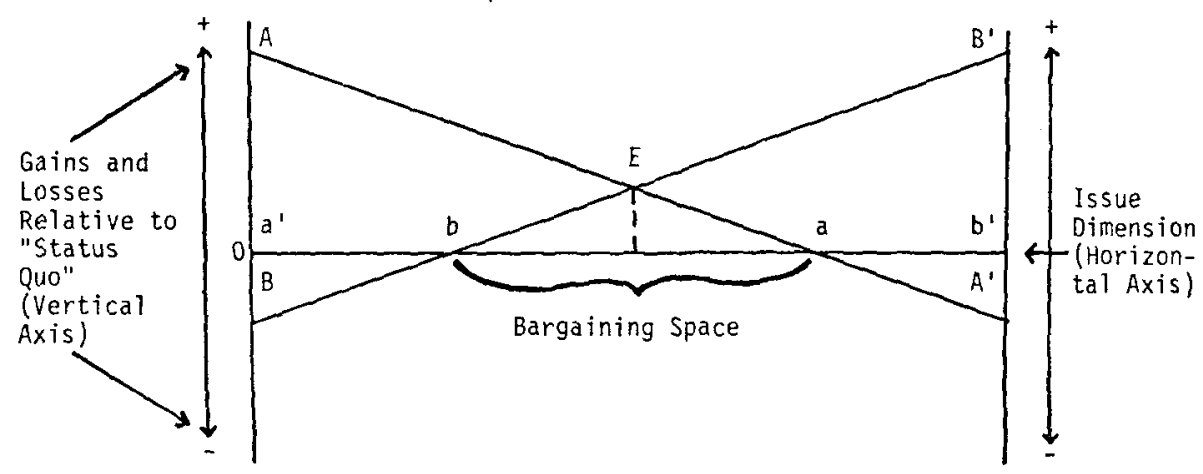

and also of the slope of the utility curves, $A--A^{\prime}$ and $B--B^{\prime}$. As is also the case for Figure 5, point $E$ in Figure 6 does not represent a stable equilibrium since each actor may be tempted to maximize his outcomes within the available bargaining space. The ability to move the outcome either to the left, as $A$ prefers, or to the right, as $B$ prefers, may be a function of strategic influence variables not captured in the game theoretical model. These strategic factors may contribute to asymmetrical outcomes in ways which will be discussed in the next section.

Issues in a negotiation, however, are not always characterized by bargaining space. Figure 7 depicts a case where the utility curves of the two actors intersect below the neutral point and where there is no overlap of positions between minimum acceptable agreements, so that all agreements producing gains for $A$ lead to losses for $B$ and vice versa. In such a case agreement is not possible without violating the assumption that no actor will settle for a solution that leaves him worse off than he would be without an agreement, i.e., which leaves him below his security level.

In expanding this basic model to take account of more than two negotiators, one must introduce the utility curves of all actors whose assent is necessary in order . to consummate an agreement. Figure 8 shows the basic bargaining model in a negotiation with four actors. Utility curves represented by lines $C-C^{\prime}$ and $D$ - - $-D^{\prime}$ are also plotted, and $c$ and $d$ represent the minimum acceptable agreements for these two new actors. In this case the bargaining space would be reduced by comparison with that depicted in Figure 6, so that bargaining space would include only a minimum common denominator of overlapping possible agreement for all relevant actors. If coalitions have formed, then the actor with the most stringent 
Figure 7. The Absence of Bargaining Space

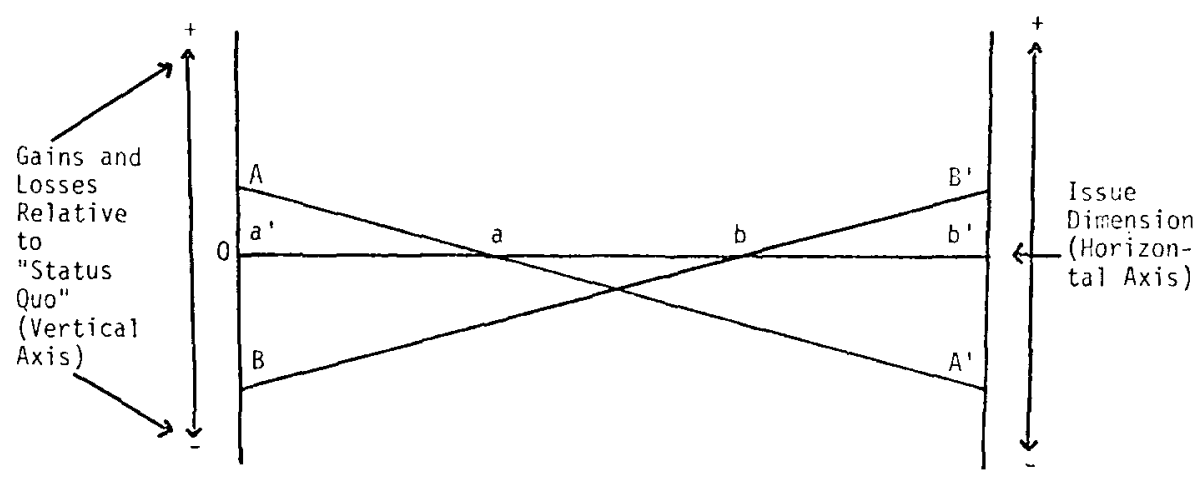

Figure 8. An N-Person Bargaining Model

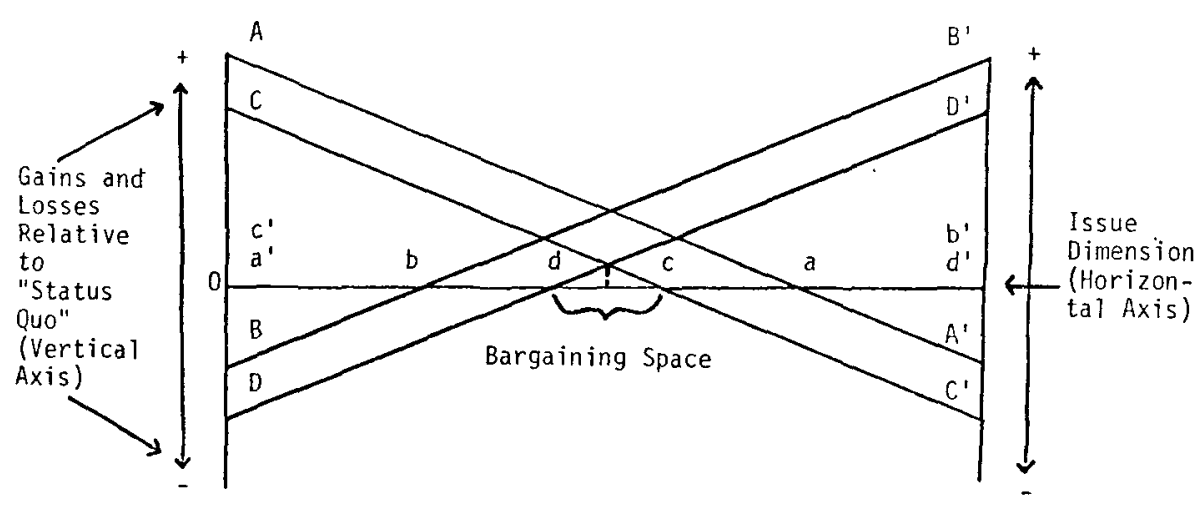


minimum acceptable position in effect sets the minimum for the coalition as a whole. In Figure 8 , if $A$ and $C$ are allies and $B$ and $D$ are also allied, then in effect $C$ sets the minimum position for his coalition and $D$ sets the minimum for his. Thus multilateral negotiations are likely to constrain the available bargaining space in that agreement must be acceptable to all of the participants whose assent is essential.

\section{The strategic or manipulative orientation}

The construction of an adequate theory of the role of asymmetry in bargaining requires the consideration of the use of information manipulation and strategic devices for influencing the behavior of others. Such a consideration involves an extension of the game theoretic model to include a more dynamic, process-oriented approach. Strategic devices may contribute to asymmetrical outcomes in two primary ways. First, they may be used to affect the information available to negotiators, by either clarifying or obfuscating the structure of the bargaining situation. Second, they may be employed to modify the actual structure of the bargaining situation to induce an actor to accept an agreement which it might otherwise not prefer.

As Young points out, the strategic approach focuses on interactions in the presence of conflicts of interests and imperfect information. ${ }^{17}$ Bargainers may try to manipulate one another's understanding about the payoffs, and they may even try to change objective payoffs. Thus manipulative theories are most likely to be appropriate to negotiations where extensive communications are possible, such as in the case of most international negotiations. Young further notes that the manipulative approach is particularly relevant to asymmetrical bargaining:

bargaining is often casually conceptualized as a phenomenon involving roughly symmetrical activities on the part of two or more purposive actors. However, situations involving manipulative bargaining may vary greatly in these terms. Thus, perfectly symmetrical bargaining is the limiting case in which the players engage in equal or identical efforts to manipulate the information conditions of each other. And perfectly asymmetrical bargaining is the other limiting case in which only one of the players makes any effort at all to manipulate the information conditions of the other(s). It seems reasonable to conclude on a priori grounds that perfectly symmetrical bargaining will seldom occur in the real world, if only because the resources and personal attributes of the players are unlikely to be identical. Situations that approximate perfectly asymmetrical bargaining, on the other hand, are probably more likely to occur in reality. ${ }^{18}$

The first means of manipulation noted above is to affect the information available to players, such as information about utilities. Although the pure game theoretical model assumes that utility schedules are perfectly known to all parties, in

${ }^{17}$ Young, p. 303.

${ }^{18}$ Ibid., p. 307. 
international negotiations this is not generally the case. Thus actors may manipulate others in an effort to deceive them about their own true utilities, especially about their minimum level for an acceptable agreement. Figure 9 depicts a case in which $A$ attempts to convince $B$ that his utilities fall along the line $A^{*}-A^{* \prime}$ rather than along line $A--A^{\prime}$, where they really fall. If $A$ succeeds in convincing $B$, then he may lead $B$ to believe that his minimum acceptable position is at point $a^{*}$. This would then move the basic solution point from $E$ to $E^{*}$, in a direction favorable to $A$. Although the original outcome would have produced payoffs at level $Q$ for both players, this new solution would raise the payoff for $A$ to level $S$ while reducing the outcome for $B$ to level $R$. Through manipulating information in this manner, that is in effect through deception, $A$ could produce an outcome which would provide him with greater payoffs at $B$ 's expense. Thus unequal capabilities to engage in such deception may produce asymmetrical outcomes.

A second means of manipulation is for one actor to influence another in order to change his utilities or in order to get him to accept agreements which he might otherwise not prefer. Theories of the influence process are directly relevant to this aspect of bargaining. Indeed, a classic definition of influence treats it "as a relation among actors in which one actor induces other actors to act in some way they would

\section{Figure 9. The Effects of Misinformation}

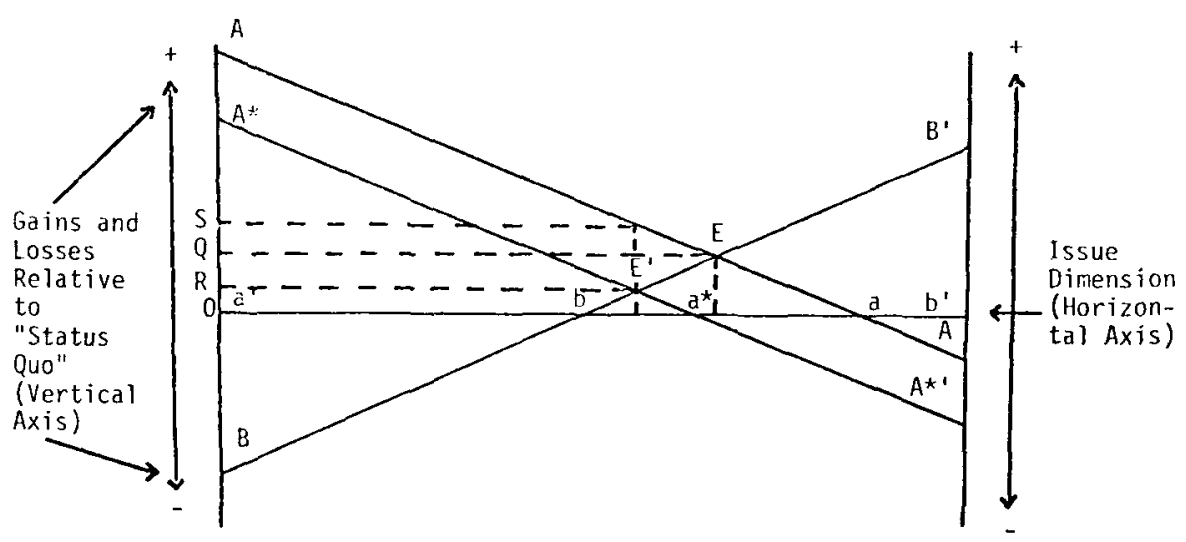


not otherwise act." 19 Harsanyi has criticized this simplest version of influence on the grounds that it fails to take into account at least two important considerations. First, it overlooks the "opportunity cost to $A$ of attempting to influence $B$ 's behavior." ${ }^{20}$ Second, it disregards "the opportunity $\operatorname{costs}$ to $B$ of refusing to do what $A$ wants him to do, i.e., of refusing to yield to $A$ 's attempt to influence his behavior." ${ }^{21}$ In other words, it overlooks the fact that the relationship between $A$ and $B$ is bidirectional and that $B$ has an option either to accede to $A$ 's influence attempt or to resist it. Harsanyi then concludes with a reformulation of the influence relationship in terms of utilities such as those contained in a game theoretic model of the bargaining relationship:

$A$ 's power over $B$ should be defined not merely as an ability by $A$ to get $B$ to do $X$ with a certain probability $p$, but rather as an ability by $A$ to achieve this at a certain total $\operatorname{cost} u$ to himself, by convincing $B$ that $B$ would have to bear the total $\cos t v$ if he did not do $X .{ }^{22}$

As Harsanyi amplifies this definition, he also stresses that power must be conceived in a "schedule sense," that is, as a function of the costs of using power in relation to other dimensions of power such as resources. ${ }^{23}$ Alker has more recently suggested that this functional treatment of influence relationships should take account of contingencies which may alter the nature of the functional relationships among "power amounts, effects, scopes, extents, strengths, net inducements, net gains, and influencer costs." ${ }^{24}$ All of these considerations may be reflected in the utility schedules and base points of the basic bargaining model depicted in Figure 6 . Harsanyi indicated, for example, that the Nash bargaining model provides a framework capable of treating the bilateral nature of influence relationships. ${ }^{25}$

Other aspects of contingent relationships may be accounted for by the employment, generally at some cost, of manipulative devices to influence the net balance of costs and gains from an outcome at any point along the issue dimension for parties to a negotiation. The decision to employ strategic devices may reflect a decision to convert the potential power of one party into actual power through the issuing of a commitment, a threat, or a promise in order to induce change in the bargaining behavior of other parties. Furthermore, as Knorr points out the external conditions (such as events in the international or domestic environments) "deter-

\footnotetext{
${ }^{19}$ Robert A. Dahl, Modern Political Analysis (Englewood Cliffs, N.J.: Prentice-Hall, 1963), p. 40.

${ }^{20} \mathrm{John}$ Harsanyi, "The Measurement of Social Power," in Martin Shubik, ed., Game Theory and Related Approaches to Social Behavior (New York: John Wiley and Sons, 1964), p. 186.

${ }^{21}$ Ibid., p. 186.

${ }^{22}$ lbid., p. 187.

${ }^{23}$ Ibid., pp. 194-95

${ }^{24}$ Hayward R. Alker, "On Political Capabilities in a Schedule Sense: Measuring Power, Integration, and Development,' in H.R. Alker, K.W. Deutsch, and A.H. Stoetzel, eds., Mathematical Approaches to Politics (San Francisco: Jossey-Bass, Inc., 1973), p. 326.

${ }^{25}$ Harsanyi, pp. $198-206$.
} 
mining the conversion of putative power into actualized power may change during the time of the bargaining process." ${ }^{26}$ Thus the dynamic aspects of the bargaining process, those aspects which make a negotiation something more than the "discovery" of an abstract "agreement point," are likely to be captured from the analysis of manipulative devices through which negotiators attempt to influence one another.

One of the most common strategic devices is the commitment, a firm statement by a negotiator that he will not compromise beyond a certain specified point. Commitments serve several functions in bargaining. In "integrative" bargaining they may be used by the parties as a device for communicating the level of minimum acceptable agreements. In this respect they may be used to improve the state of information. On the other hand, in "distributive" bargaining the commitment may be used by each party in trying to exaggerate its minimum level of agreement in a direction favorable to the party employing it. In this case commitments may be used to reinforce deceptive manipulations of the type discussed earlier. Thus, if $A$ tries to commit himself to a position just to the right of $b$ in Figure 6 and is successful in doing so, then $B$ has no choice but to accept an agreement there at little gain for himself and at a substantial gain for $A$. Actors may try to make their commitments credible by engaging in actions preventing themselves from compromising, figuratively "burning their bridges behind them." 27

There are several paradoxes in the use of commitments. For one thing, if both parties use them simultaneously, they may create a situation like that depicted in Figure 7 where there is no overlapping bargaining space. If these commitments are believed to represent true minimal conditions by both sides, then the actors may simply break off negotiations. Thus a stalemate would result even though in principle both actors could have gained from an agreement. If the commitments are not believed, then concessions may commence. But the first concession is hard to make since the side making it reveals that its commitments were not really valid. The first concession may thus reduce the credibility of further commitments, leading to a chain reaction of concessions, usually producing asymmetrical outcomes.

Another possible source of difficulty in the use of commitments is that each party may not be aware prior to their use, if ever, of the true utilities of the other party. Thus one side may misjudge the minimum acceptable position of the other side and commit itself to a more extreme position. In Figure 6, if $A$ committed himself to a point left of $b$, then $B$ would find agreement at this point unacceptable. This would then leave $A$ with the hard choice of either scuttling the potentially profitable agreement or beginning a chain of concessions which could eventually leave him worse off than if he had never made such an overly ambitious commit-

\footnotetext{
${ }^{26}$ Klaus Knorr, The Power of Nations: The Political Economy of International Relations (New York: Basic Books, 1975), p.20.

${ }^{27}$ On this point see the discussion of bargaining power in Thomas C. Schelling, The Strategy of Conflict (Cambridge, Mass.: Harvard University Press, 1960), pp. 22-28.
} 
ment in the first place. ${ }^{28}$ As Schelling observes, commitments "run the risk of establishing an immovable position that goes beyond the ability of the other to concede, and thereby provoke the likelihood of stalemate or breakdown." 29

Commitments may thus bring about asymmetrical outcomes in negotiations in several ways. First, they give an advantage to the intelligent bargainer who can use them judiciously. An actor who can commit himself credibly without becoming overcommitted will generally have a significant advantage in influencing the outcomes. Second, an actor willing to run the risk of a breakdown of negotiations through his commitments may also have an advantage. An actor's commitment will be more credible if the costs to the actor of sticking to his commitments, even at the risk of stalemate, are relatively low. Thus commitments should generally reinforce the tendency already noted in the game theoretic model to give an advantage in bargaining to the player with the lowest costs from noncooperative outcomes.

The second bargaining strategy is the threat, which may be subdivided into two classes. The first class is a threat by one party to cut off negotiations and to leave both parties at the status quo. Thus, with regard to the diagram in Figure 6, $A$ may threaten $B$ by saying that unless $B$ accepts a solution just to the right of point $b$, he will break off negotiations and leave $B$ at point $b$, which is worse for him than any point to the right of $b$ where he would make at least some profit, regardless of how small. This type of threat is essentially the same as that discussed by Nash and other game theorists.

A second class of threat goes beyond the bounds of the original game and introduces the notion of side payments. In this case $A$ may tell $B$ that, if $B$ does not agree to a solution favored by $A$, then $A$ will remove a reward or apply a punishment. This in effect alters the nature of the game by increasing the costs of nonagreement relative to agreement for $B$. This is depicted in Figure 10 as a movement of his utility curve prior to the threat $\left(B--B^{\prime}\right)$ in a northwesterly direction after the threat $\left(B^{*}--B^{* \prime}\right)$. In this case the new point of agreement which would maximize joint utilities is moved well to the left in the direction favored by $A$. $A$ may now even be able to get a solution to the left of $b$, which would previously have been unacceptable to $B$. Furthermore, $A$ 's payoffs increase from $Q$ to $R$. Because of the increased costs of nonagreement for $B$, a solution at this point is now profitable in comparison with no agreement, although in terms of the pre-threat utilities his payoffs are reduced from $Q$ to $S$, a negative result.

The success of a threat depends upon several things. It depends heavily on the credibility of the threat, namely whether or not $B$ believes that $A$ will carry it out. $B$ 's expected utility curve will generally move only as a function of the cost of the threat to $B$ times $B$ 's perception of the probability that $A$ will carry it out. Thus, as

\footnotetext{
${ }^{28}$ Although this latter argument is partly consistent with the so-called "falling domino" theory so widely propagated by American official spokesmen during the Vietnam war, it also makes it clear that an actor can bring such a phenomenon on itself through committing itself to a position which goes beyond the realistic possibility of concessions by the other party.

${ }^{29}$ Schelling, p. 28.
} 


\section{Figure 10. The Effects of Threats and Promises}

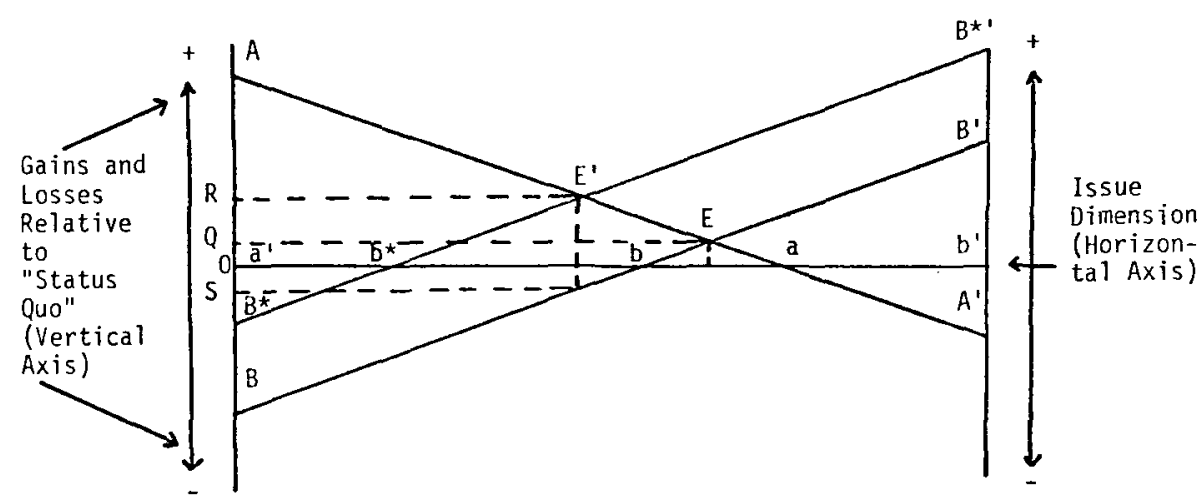

Schelling remarks, "The threat is ineffectual unless the threatener can rearrange or display his own incentives so as to demonstrate that he would, ex post, have an incentive to carry it out." ${ }^{30}$ Furthermore, $A$ must convince $B$ that he has the capabilities to carry out a threat. To this degree, at least, the party with the greater resource base is at an advantage in its ability to threaten credibly. Also important is the bargaining reputation of the threatener, namely whether or not he is known to carry out his threats and has an incentive to do so. Finally, a party may be more successful in the use of threats to change utilities if it is willing to run the risk of having his bluff called, thus leading not only to the need to execute the threat but also to the absence of an agreement which might otherwise have been profitable. Once again, the party with more to lose from the failure to cooperate is left at a disadvantage when it comes to the use of threats because he may be reluctant to run the risk of nonagreement if his bluff is called and the threatened party refuses to concede.

A number of social-psychological studies have looked at the effects of threats upon bargaining in laboratory experiments. Although the results of this research are sometimes weak and divergent, there does seem to be some consensus that threats may be functional for communications in "integrative" bargaining situations. In this case, they may be used to mark emphatically minimum positions and thus help to clarify the range of available bargaining space. In "distributive" bargaining, however, threats may produce results which will be less than Pareto-optimal, that is, which will reduce the joint payoffs for both parties. In this respect, they may lead to outcomes which are somewhat different from those which would be predicted by 
"pure" game theory in the absence of strategic considerations. When threats are used by one party only, they will reduce the payoffs less of the party using them than of his victim. In this context, they will tend to lead to more asymmetrical outcomes, although both parties are likely to be less well off than if threats had never been employed. ${ }^{31}$

The third strategic device is the promise, which is the logical inverse of the threat. In a promise party $A$ may inform $B$ that, if he accepts an agreement at a point favored by $A$, then $A$ will provide him with a reward or remove a punishment. This has the effect of raising the gains of agreement relative to no agreement. Relative to the neutral point in Figure 10, it has the same effect as a threat, namely to move $B$ 's utility curve in a northwesterly direction. It differs from a threat only in that a promise adds to the gains associated with an agreement, whereas a threat adds to the costs of nonagreement. Like a threat, however, it may open up new possibilities for agreement. In addition its success depends heavily on the credibility which the recipient places in it. This is likely to be a function as well of the past performance of the promiser in executing promises and of the resources available for carrying out the promises.

\section{Theoretical conclusions}

The attempt thus far has been to outline a tentative theoretical conceptualization of bargaining under conditions of structural asymmetry. This discussion began with a simple game theoretical formulation which suggested that asymmetrical outcomes in negotiations could be predicted on the basis of the relative costs to negotiators of noncooperative outcomes, represented by the status quo point as well as by the threat to be left at one's own security level. This formal conceptualization was then translated into a basic bargaining model which was more directly applicable to international negotiations. Such a conceptualization introduced dynamic elements of the bargaining process, especially the employment of manipulative techniques for modifying actors' information or their utilities. Thus the ability to influence the behavior of another actor is an important factor affecting the symmetry or asymmetry of bargaining outcomes. Although the theoretical conceptualization drew upon several different theoretical traditions, there was a convergence around several propositions which are at least logically consistent with the basic assumptions of the conceptual framework. The following propositions, then, emerge:

1) Negotiations will tend to result in asymmetrical outcomes favoring the negotiating party which has:

a) the least losses associated with being left at the status quo point of nonagreement, or

\footnotetext{
${ }^{31}$ For a review of this laboratory research see Jack Sawyer and Harold Guetzkow, "Bargaining and Negotiation in International Relations," in Herbert Kelman, ed., International Behavior (New York: Holt, Rinehart, and Winston, 1965), pp. 508-11, and Daniel Druckman, Human Factors in International Negotiation: Social Psychological Aspects of International Conflict (Beverly Hills, Cal.: Sage Professional Papers in International Studies, 1973), pp. 68-74.
} 
b) the least losses resulting from being threatened to be left at his own security level.

2) Negotiations will tend to result in asymmetrical outcomes favoring the negotiating party which has:

a) the greatest resources available to reinforce his strategic behavior, including commitments, threats, and promises, or

b) the least losses in the event that the use of strategic devices results in a stalemate, thus leaving him at the status quo point of nonagreement (i.e., the same result as that predicted in 1-a above).

Having explored some of the logical foundations of these propositions, in the next section I will investigate their empirical plausibility through a case study of the negotiations on Security and Cooperation in Europe.

\section{An empirical application: "basket one" of the Conference on Security and Cooperation in Europe}

\section{Background to the CSCE negotiations}

The Conference on Security and Cooperation in Europe (CSCE) was the first all-European multilateral conference since World War II, with the objective of improving relations among European states on a wide range of issues. The conference was composed of 35 participants, including all states of Europe plus the United States and Canada. Although it was itself a conference of limited duration and thus does not formally constitute an international organization, it was the aim of its proponents to create a new, multilateral system of security in Europe. In this sense the CSCE may be considered as a proto-international organization, in that many participants want to establish this new system of interaction on an ongoing basis. Although they did not rely heavily on an institutional structure at the outset, a decision was made to hold a review conference in Belgrade in 1977, thus establishing the principle that participants might meet at regular intervals to review progress and to update and strengthen the final act. In short, the CSCE purports to have laid the basis for a European-wide security system. At the time of this writing it is not possible to tell whether it will evolve into a more enduring and formal organization, perhaps supplanting or at least reducing the role of the military alliances and the economic blocs in European political affairs.

The CSCE is a good case for the application of a theory of negotiations focusing on the concept of asymmetry. Although the Conference was formally composed of 35 sovereign and independent entities, its members in fact tended to caucus in blocs, including the two alliances of NATO and the Warsaw Pact plus a group of nonaligned states. On a number of occasions within these caucuses disputes evidently arose between the bloc leaders and their smaller allies. In addition, a good deal of bargaining took place between the two major power blocs and the third 
group of nonaligned states. The nonaligned states of Europe, of course, did not differ significantly from most of the aligned states on categories of wealth and national power, with the exception of the two superpowers. Thus their role was somewhat different from that of the nonaligned actors in more universal bodies such as the United Nations. Furthermore this group, which included Yugoslavia and Spain, was not ideologically homogeneous. Nonetheless, these nations did share a common structural role and often did act in concert to modify the positions of the power blocs or to mediate between them. Thus the role which these nations played in the CSCE may give some indication of the degree to which the less powerful nations, both in terms of their own resources and their potential to aggregate their resources with those of their allies, were able to influence the more powerful bloc actors in the negotiations.

The negotiations began at the preparatory level in November 1972, though they were officially inaugurated at a meeting of foreign ministers at Helsinki in July 1973. A working phase then began in Geneva in September 1973 and continued through July 19, 1975, when it was announced that a final document would be signed in Helsinki on July 31-August 1, 1975. The final document contained three parts or "baskets," the first dealing with "security in Europe," the second with cooperation in the fields of economics, science, technology, and the environment, and a third treating cooperation in humanitarian concerns.

The focus here will be on the negotiations on the first of these major headings, the question of security in Europe. This section dealt with three broad categories of issues. The first involved a declaration of ten "principles guiding relations between [sic] states," including respect for sovereignty, refraining from the use of force, use of peaceful means to settle disputes, non-intervention in internal affairs, respect for human rights, and abidance by the rules of international law. The second section dealt with certain confidence-building measures (CBM's) designed to improve mutual trust among the states of Europe. This included provisions for the prior notification of major military maneuvers, the voluntary notification of major military movements, and finally some general declarations about détente and disarmament. A third issue, which did not find its way into the final agreement, centered around a project promoted by the Swiss to establish procedures for the peaceful settlement of disputes.

The goal of the CSCE was to arrive at an agreement that could be signed by all participants. Thus unanimity among the 35 participants was generally required in order to reach agreement. Of course, this doesn't mean that every country agreed entirely with every provision, as there were some tradeoffs where countries sacrificed a preferred position on one issue in order to win their position on another issue. But in general the final act is reflective of the "lowest common denominator" of agreement which was required in order to achieve such unanimity.

\section{Research procedures}

There are a number of significant problems with applying a conceptualization 
of negotiations based on game theory to "real world" international negotiations. While the game theoretic orientation and its extension in theories of bargaining strategy and the social psychology of bargaining may be suggestive of hypotheses, the problems with operationalizing the crucial variables identified by such theories are extremely severe. This study is no exception to this generalization, as very grave problems of variable operationalization have been encountered. Since there is no good method currently available to measure utilities, for example, one must do the best one can to estimate these on the basis of rather scanty information. In this research, extensive interviews with various participants in the CSCE negotiations were conducted both in the course of the negotiations in 1974 and afterwards in 1975-76. This provided some clues to the relative preferences of the actors, though it did not supply any clearcut method for precisely measuring utilities. Therefore, we must settle for relatively rough measures of this concept and of others in the theory. I shall attempt throughout, however, to evaluate the plausibility of the hypotheses not only in the light of some tentative "tests" of these hypotheses but in the context of a qualitative examination of them as well.

The hypotheses suggested two basic independent variables. The first is the "threat potential" of the participants as reflected in their utility schedules. Although this variable enters in somewhat different forms in propositions 1-a, 1-b, and 2-b, these differences are too subtle to be identified empirically by any available research strategy. Therefore, we have been forced to consider only an approximation of the losses which each nation would receive from an outcome of no agreement relative to what they might achieve by an agreement. Although there are many differences among the states of Europe in this regard, most of the major differences appear to be closely related to structural differences, to the different roles which these states played in the international system. Such structural distinctions no doubt mask many important differences; nevertheless, one of the most interesting aspects of these negotiations was the manner in which nations with quite different ideological orientations, such as Spain and Yugoslavia, managed to cooperate closely, largely on the basis of shared structural roles in the conference. The following categories have been constructed, ranging from those states which appear to be the most dissatisfied with the status quo and thus are likely to receive the greatest losses from the failure to agree (category 1) to those which are most satisfied and would stand to lose the least from the failure to reach a cooperative outcome (category 5).

Category 1: The nonaligned nations, which often feel trapped between the two superpower alliances in Europe: Austria, Cyprus, Finland, Ireland, Liechtenstein, Malta, Monaco, San Marino, Spain, Sweden, Switzerland, Yugoslavia, and the Holy See.

Category 2: The divided states, which were left in a so-called "artificial" situation following World War II: the Federal Republic of Germany and the German Democratic Republic.

Category 3: The most restless members of the two alliances, seeking the greatest degree of independence from the superpowers: France and Rumania.

Category 4: The other nonsuperpower members of the two alliances: Belgium, Bulgaria, Canada, Czechoslovakia, Denmark, Great Britain, Greece, Hungary, 
Iceland, Italy, Luxembourg, The Netherlands, Norway, Poland, Portugal, and Turkey.

Category 5: The two superpowers which desire to retain some degree of domination over their European clients: the Soviet Union and the United States.

The second independent variable, included in proposition $2-\mathrm{a}$, is the resources which the participants can bring to bear to support influence attempts. ${ }^{32}$ Data were collected on both general economic and human resources as well as certain military resources, since these negotiations were very much involved with military and strategic considerations. These include general economic strength indicators (GNP, population, and GNP per capita) and general indicators of military strength (total military expenditures, military expenditures/GNP, the size of the armed forces, and military expenditures per capita) ${ }^{33}$ Finally, since I was primarily concerned with security within Europe, I also looked at similar indicators of military resources for the European area only (armed forces stationed in Europe, divisions stationed in Europe, tanks stationed in Europe, and air forces stationed in Europe) ${ }^{34}$

The dependent variable, influence over the outcome of the negotiations, was also difficult to measure. I have, however, been able to trace the original authorship of many sections of the CSCE final act for "basket one" on the basis of a limited set of documents produced by the working subcommittee in Geneva ${ }^{35} \mathrm{I}$ have thus computed the number of words in the Final Act's section on Principles and on Confidence Building Measures that each country first introduced, assuming that the portion of the text authored by each country is a rough indicator of its influence in the final deliberations. There are some distinct problems with this procedure, however. First, only about 50 percent of the text could be traced to a specific country. The remainder was attributed in the coding to the subcommittee as a whole, although this included language on major provisions evidently worked out in purely verbal sessions without any written proposals, as well as simple changes in the text introduced by the committee for reasons of grammar or style. Furthermore, there was evidently some division of labor within the bloc caucuses, as on various issues one country was apparently chosen to present the position of its bloc. Thus it was

\footnotetext{
${ }^{32}$ It is evident that resources can provide only a partial indicator of the ability to influence, and that conceptualizations of influence based upon resources must also deal with this concept only in what Alker, pp. 330-32, has described as an "incomplete point sense." Nevertheless, more complex conceptions of power are extremely difficult if not impossible to operationalize, so for the moment we must employ merely a rough indicator of influence capability treated in a relatively simple conceptual sense.

${ }^{33}$ These data were obtained from the US Arms Control and Disarmament Agency, World Military Expenditures and Arms Transfers, 1965-1974 (Washington, D.C.: U.S. Government Printing Office, 1976); all data are from 1974.

${ }^{34}$ These data were from World Armaments and Disarmament: SIPRI Yearbook 1974 (Cambridge, Mass.: MIT Press, 1974); they apply only to the members of the NATO alliance and the Warsaw Treaty Organization.

${ }^{35}$ The following documents were examined: CSCE Documents II/A/1 (19 September 1973) through II/A/36 (6 June 1975); II/A/101 (8 February 1974) through II/A/138 (1 April 1975); II/C/I (19 September 1973) through II/C/17 (12 March 1974); II/C/101 (13 March 1974) through II/C/121 (20 July 1975).
} 
often difficult to tell whether a particular draft was presented on a purely national initiative or as a result of caucus deliberations. In these cases, since these nations were not formally acting on behalf of blocs, the text has been coded as having been authored by the individual country. Finally, the percentage of the text authored, even if the data were fully accurate, is not an ideal indicator of the amount of influence over the final agreement. Since no better indicator was readily available, this has been used as a rough approximation of influence, although the limitations of this indicator must clearly be kept in mind in evaluating the results.

Due to the severe limitations of this analysis, however, several significant, sensitive, and highly debated issues were also selected for qualitative analysis. This type of analysis is patterned roughly after that of Dahl in his studies of community power, ${ }^{36}$ although an attempt has been made to take account of some of the most significant criticisms of these procedures. In this analysis I shall look for any significant indications of the exercise of asymmetrical influence in the bargaining over several crucial issues, some of which are not reflected in the final act.

\section{The textual analysis}

The basic results of this analysis of the CSCE texts for "basket one" are presented in Table 1. A quick observation of this table indicates that six countries accounted for 77 percent of the attributable text and 38 percent of the entire text: Yugoslavia, the Soviet Union, the United Kingdom, France, Belgium, and the United States. One factor accounting for this result is that the conference did often operate on a bloc basis in spite of pretensions to the contrary. Thus one or two countries were often the primary spokespersons for their bloc on most issues.

The results for the hypothesis about the role of "threat potential" in influencing the outcomes of the CSCE are noted in Table 2. Here it is evident that the category 5 nations, the two superpowers, did exert the greatest average influence on the agreement as predicted. On the other hand, the category 3 group, composed of the alliance mavericks, France and Rumania, was somewhat more influential than predicted. Although the average influence of the nonaligned nations was relatively low, as predicted, there were several exceptions here with Yugoslavia being the most notable case. The Yugoslavs were the original authors of approximately 20 percent of the identifiable text in spite of being in a relatively weak position in terms of both threat potential and resources. On the other hand, the Yugoslavs apparently perceived considerable positive gain from an agreement which may have encouraged them to take a considerably more active role in the conference than most other nations, and this seems to have produced results in this case which contradict the hypothesis about low threat potential leading to low effectiveness in influencing outcomes. The Yugoslavs viewed the CSCE as a means to begin the breakup of the

\footnotetext{
${ }^{36}$ See Robert A. Dahl, Who Governs? (New Haven, Conn.: Yale University Press, 1961).
} 
Table 1 National contribution to the text of "basket one" of CSCE

\begin{tabular}{|c|c|c|c|c|c|c|}
\hline Country & $\mathbf{A}$ & $\mathbf{B}$ & $\mathbf{C}$ & D & $\mathbf{E}$ & $\mathbf{F}$ \\
\hline Yugoslavia & 261 & 30 & 291 & 10.01 & 20.15 & 1 \\
\hline USSR & 101 & 135.5 & 236.5 & 8.13 & 16.38 & 2 \\
\hline Great Britain & 62 & 173 & 235 & 8.08 & 16.27 & 3 \\
\hline France & 172 & $\mathbf{0}$ & 172 & 5.91 & 11.91 & 4 \\
\hline Belgium & 116 & $\mathbf{0}$ & 116 & 3.99 & 8.03 & 5 \\
\hline United States & 18 & 44.5 & 62.5 & 2.15 & 4.33 & 6 \\
\hline Rumania & 20 & 24 & 44 & 1.51 & 3.05 & 7 \\
\hline Sweden & $\mathbf{0}$ & 41 & 41 & 1.41 & 2.84 & 8 \\
\hline GDR & 33 & 0 & 33 & 1.13 & 2.29 & 9 \\
\hline Austria & $\mathbf{0}$ & 30 & 30 & 1.03 & 2.08 & 11.5 \\
\hline Cyprus & $\mathbf{0}$ & 30 & 30 & 1.03 & 2.08 & 11.5 \\
\hline Finland & 0 & 30 & 30 & 1.03 & 2.08 & 11.5 \\
\hline Switzerland & $\mathbf{0}$ & 30 & 30 & 1.03 & 2.08 & 11.5 \\
\hline Poland & 0 & 27 & 27 & 0.93 & 1.87 & 14 \\
\hline Malta & 14 & 0 & 14 & 0.48 & 0.97 & 15 \\
\hline Netherlands & 13 & 0 & 13 & 0.45 & 0.90 & 16.5 \\
\hline Spain & 3 & 10 & 13 & 0.45 & 0.90 & 16.5 \\
\hline FRG & 8 & 0 & 8 & 0.28 & 0.55 & 18 \\
\hline Holy See & 7 & 0 & 7 & 0.24 & 0.48 & 19.5 \\
\hline Turkey & 7 & 0 & 7 & 0.24 & 0.48 & 19.5 \\
\hline Italy & 4 & 0 & 4 & 0.14 & 0.28 & 21 \\
\hline SUBTOTAL & 839 & 605 & 1444 & 49.65 & 100.00 & \\
\hline Subcommittee & 861 & 603 & 1464 & 50.35 & - & \\
\hline TOTAL & 1700 & 1208 & 2908 & 100.00 & 100.00 & \\
\hline
\end{tabular}

Explanation of columns:

A) Number of words of text authored in section of CSCE on "Principles Guiding Relations between Participating States.'

B) Number of words of text authored in section of CSCE on "ConfidenceBuilding Measures...."

C) Total number of words attributed to nation in "basket one" of CSCE.

D) Percentage of total text authored by each nation.

E) Percentage of attributable text authored by each nation.

F) Rank-order of frequency of contribution to text.

Table 2 Average number of words authored by nations in each category of "threat potential"

Percent of words

$\begin{array}{lr}\text { Category 1: } & 37.4 \\ \text { Category 2: } & 20.5 \\ \text { Category 3: } & 108.0 \\ \text { Category 4: } & 25.1 \\ \text { Category 5: } & 149.5\end{array}$


bloc structures which have dominated Europe since the end of World War II. They felt that this infringed upon the natural interactions of independent states, and they hoped that the CSCE would begin to restructure European relations on a multilateral basis. To advance these principles Yugoslavia became a leader among the nonaligned nations, assuming a role traditionally taken by Sweden in arms control conferences, although the latter nation was the second ranking contributor among the nonaligned states to this part of the CSCE.

According to these indicators, the least influential states on the average were the two Germanies, with only 41 words credited to them combined, totalling less than 3 percent of the identifiable text. By contrast, the major exception to the hypothesis as already noted was for the case of France and Rumania, which together accounted for 216 words of text or over 13 percent of the identifiable total. Like Yugoslavia, both probably played an active role in order to further their goal of using the CSCE as a means for breaking up tight bloc structures in Europe, which both viewed as providing excessive constraints on their freedom of action.

Turning next to the hypothesis about structural factors, one must look primarily at resources as a rough indicator of the ability to employ credible bargaining strategies and thereby exert influence, although I am aware of the limitation of treating power relations solely in "an incomplete point sense." 37 The results are displayed in Table 3. Pearson product-moment correlations are calculated between a variety of resource indicators and the text authorship, including the entire "basket one" text, as well as a breakdown of the text for the part dealing only with principles and the part dealing with confidence-building measures. Among the

\section{Table 3 Correlations (and significance levels) between text authorship and indicators of national resources}

Textual provisions

\begin{tabular}{llll}
\hline RESOURCE INDICATORS & ENTIRE TEXT & PRINCIPLES TEXT & \multicolumn{1}{c}{ CBM'S TEXT } \\
\hline Military expenditure & $.35(\mathrm{p}=.12)$ & $.13(\mathrm{p}=.58)$ & $.49(\mathrm{p}=.02)^{* *}$ \\
Mil. expenditure/GNP & $.38(\mathrm{p}=.10)^{*}$ & $.25(\mathrm{p}=.29)$ & $.35(\mathrm{p}=.13)$ \\
Total armies & $.41(\mathrm{p}=.07)^{*}$ & $.19(\mathrm{p}=.42)$ & $.51(\mathrm{p}=.02)^{* *}$ \\
Mil. expenditures/capita & $.34(\mathrm{p}=.13)$ & $.13(\mathrm{p}=.58)$ & $.46(\mathrm{p}=.03)^{* *}$ \\
Armies in Europe & $.28(\mathrm{p}=.37)$ & $.17(\mathrm{p}=.60)$ & $.26(\mathrm{p}=.41)$ \\
Divisions in Europe & $.24(\mathrm{p}=.46)$ & $.00(\mathrm{p}=1.00)$ & $.36(\mathrm{p}=.26)$ \\
Tanks in Europe & $.40(\mathrm{p}=.20)$ & $.11(\mathrm{p}=.73)$ & $.49(\mathrm{p}=.10)^{* *}$ \\
Mil. aircraft in Europe & $.57(\mathrm{p}=.05)^{* *}$ & $.28(\mathrm{p}=.37)$ & $.58(\mathrm{p}=.05)^{* *}$ \\
GNP & $.22(\mathrm{p}=.36)$ & $.06(\mathrm{p}=.80)$ & $.33(\mathrm{p}=.16)$ \\
GNP/capita & $-.01(\mathrm{p}=.97)$ & $-.07(\mathrm{p}=.78)$ & $.08(\mathrm{p}=.73)$ \\
Population & $.37(\mathrm{p}=.10)^{*}$ & $.14(\mathrm{p}=.54)$ & $.50(\mathrm{p}=.02)^{* *}$ \\
\hline
\end{tabular}

$*_{p} \leqslant .10$.

${ }^{* *} p \leqslant .05$.

${ }^{37}$ Alker, p. 326. 
general resource variables, only population was significantly related to the authorship of the text, and this relationship was strong only with regard to the CBM part of the text. In general, then, more populous nations exerted a greater impact on the outcome of negotiations than did smaller ones. However, neither GNP nor GNP per capita was significantly related to the negotiation outcome. In this correlation, there are three significant outliers which probably drastically reduced the level of the relationship. Yugoslavia and Rumania both made a positive contribution to the Helsinki agreement greater than would have been predicted on the basis of their resources, whereas West Germany made a substantially less significant contribution than would have been predicted.

Turning next to the measures of military strength, Table 3 indicates somewhat stronger relationships in a number of cases, although all relationships are strongest for the portion of the text dealing explicitly with military matters, namely the section on confidence-building measures. Here relationships are significant at better than the .05 level for total military expenditures, military expenditures per capita, total size of the army, and the number of aircraft stationed in Europe. Since the Helsinki agreement dealt particularly with military maneuvers and troop movements in Europe, it is not very surprising that the most militarily powerful nations would have exerted the greatest impact over this section of the final act.

To summarize the results thus far, it is apparent that the variable of "threat potential," albeit very crudely measured, seemed to account to some degree for outcomes in "basket one" of the CSCE better than general indicators of resources or power base. The one real exception, however, is that on issues dealing specifically with military security, the militarily most powerful nations clearly seemed to exert the greatest influence over the outcomes. In this case the basic structural asymmetries among the participating nations seem to have had a significant impact.

Finally, an examination of the data broken down by blocs, as presented in Table 4, may suggest several other interesting conclusions. First, the nonaligned bloc together accounted for just about one-third of the attributable text, with Yugoslavia accounting for almost 60 percent of that figure. Thus any negative impact of the lack of resources or threat potential by these nations may have been offset by the positive benefits which they saw emerging from such an agreement and consequently by their activism both as mediators between the two "Cold War" blocs and as initiators of positions not taken by either of these two opposing blocs. Second, comparing the impact of the two traditional alliances, it is clear that NATO was more influential overall than the Warsaw Pact, with the former accounting for 42.8 percent of the attributable text and the latter only 23.6 percent. Of course, one must recall that there were 15 NATO nations participating in the CSCE against 7 Warsaw Pact nations. Perhaps their greater number combined with greater overall resources and threat potential enabled them to exert a substantial impact on the conference. Third, the distribution of influence as reflected in text authorship among the NATO nations is generally fairly even among four nations which accounted together for about 95 percent of the total NATO contribution. By contrast, the Soviet Union itself accounted for almost 70 percent of the Warsaw Pact con- 
Table 4 Data broken down on a bloc-by-bloc basis

\begin{tabular}{lcc} 
A) NATO: & Words & Percent of NATO-authored text \\
\hline United Kingdom & 235 & $38.1 \%$ \\
France & 172 & $27.9 \%$ \\
Belgium & 116 & $18.8 \%$ \\
United States & 62.5 & $10.1 \%$ \\
Netherlands & 13 & $2.1 \%$ \\
FRG & 8 & $1.3 \%$ \\
Turkey & 7 & $1.1 \%$ \\
Italy & 4 & $0.6 \%$ \\
\hline TOTAL & 617.5 & $100 \%$
\end{tabular}

NATO PERCENT OF TOTAL TEXT: $42.8 \%$

B) WARSA W PACT Words Percent of Warsaw Pact-authored text

\begin{tabular}{lcc}
\hline Soviet Union & 236.5 & $69.5 \%$ \\
Rumania & 44 & $12.9 \%$ \\
GDR & 33 & $9.7 \%$ \\
Poland & 27 & $7.9 \%$ \\
\hline TOTAL & 340.5 & $100 \%$
\end{tabular}

WARSAW PACT PERCENT OF TOTAL TEXT: $23.6 \%$

\begin{tabular}{lcc} 
C) NONALIGND & Words & Percent of non-aligned-authored text \\
\hline Yugoslavia & 291 & $59.9 \%$ \\
Sweden & 41 & $8.4 \%$ \\
Austria & 30 & $6.2 \%$ \\
Finland & 30 & $6.2 \%$ \\
Cyprus & 30 & $6.2 \%$ \\
Switzerland & 30 & $6.2 \%$ \\
Malta & 14 & $2.9 \%$ \\
Spain & 13 & $2.7 \%$ \\
Holy See & 7 & $1.4 \%$ \\
\hline TOTAL & 486 & $100 \%$
\end{tabular}

NONALIGNED PERCENT OF TOTAL TEXT: $33.7 \%$ 
tribution, thus dominating its bloc more clearly than any single nation dominated the NATO bloc. There are several possible explanations for the more direct and dominating role played by the Soviet Union in these negotiations in comparison with the United States. The Soviet Union does seem to dominate its Eastern European allies to a greater degree than the United States dominates its allies in Western Europe. In addition, the Soviet Union had a more direct interest in the issues before the CSCE, which was basically a conference of European states. The USSR thus participated actively in the discussion of all issues since it would be directly affected by all of the provisions of the agreement. By contrast, the United States was a participant in these negotiations only as a result of a special invitation, largely because of the US role in Germany and of the presence of US troops in Europe. The Americans thus tried to avoid playing an excessively active role except on those issues, such as the CBMs, which affected them directly.

\section{Analysis of selected critical issues}

One major limitation of the analysis undertaken so far is that it takes into account only the positive contributions made to the outcome of the negotiations as reflected in the final text. Yet numerous studies of power and influence have suggested that asymmetries may be best reflected not in the power over specific positive decisions but in negative power, including the power to veto proposals or the power to prevent decisions from ever being made, the "power of nondecision-making." ${ }_{38}$ Although the data are not available to give a systematic test to the hypothesis about asymmetrical bargaining in this sense, it is possible to undertake a qualitative analysis of the decisions and "non-decisions" on several hotly contested issues in the CSCE on the basis of evidence obtained from CSCE working documents and from interviews with participants.

I shall first examine some disputes concerning several of the ten "principles" about security in Europe. The first principle, dealing with "sovereign equality, respect for rights inherent in sovereignty," provided the basis for several disputes. In particular, Rumania made several significant proposals for this section which did not appear in the final text. These Rumanian proposals included the right of all states to participate equally in "the solution of all problems pertaining to security and cooperation in Europe," respect by every state for all aspects of the individual character of every other state, and the respect of "the sovereign right to make use of the natural and other resources within its territory in a manner corresponding to its interests. ${ }^{39}$

These proposals were clearly intended to enhance Rumanian independence from Soviet domination of bloc affairs. Although there is no direct evidence to

\footnotetext{
${ }^{38}$ Peter Bachrach and Morton S. Baratz, "Decisions and Non-Decisions: An Analytical Framework," American Political Science Review, Vol. 57 (September 1963).

${ }^{39} \mathrm{CSCE}$ Document II/A/18, 28 January 1974.
} 
indicate why these provisions were not adopted, it is likely that the Soviet Union effectively exercised a veto over the inclusion of these provisions.

One of the most important issues of the CSCE also arose over one sentence in principle 1 concerning national boundaries. The wording of the final agreement was suggested by an American draft: "They [the participating States] consider that their frontiers can be changed, in accordance with international law, by peaceful means and by agreement." 40 The government of the Federal Republic of Germany issued what amounted to a threat by making the acceptance of this principle an absolute condition for their acceptance of principles, especially the third, concerning "the inviolability of frontiers." This provision, however, did not appear in any committee drafts prior to the final one, suggesting that it was heavily debated. The West Germans, however, insisted upon maintaining some possibility for the peaceful reunification of Germany, to avoid the charge domestically that they were ratifying in the CSCE the permanent division of the country. Since a CSCE agreement without the participation of the US or the FRG would have been dramatically weakened, it is likely that they were able to get their way on this issue in spite of the opposition of the Warsaw Pact states. This is one case in which only a very small number of words of text was involved but where the threat potential of the two most powerful Western nations was brought to bear successfully in one of the most hotly debated issues considered for "basket one" of the CSCE.

With regard to the second principle, that of "refraining from the threat or use of force," another Rumanian proposal of some import was vetoed. This extended the principle of the non-use of force to include nonintervention in civil wars. In a draft proposal on this principle the Rumanians suggested the following provisions: "The participating States shall also refrain from organizing and encouraging acts of civil war, participating in them, assisting them or tolerating on their own territory activities organized with a view to perpetuating such acts, when the acts mentioned involve the use or threat of force." 41 This proposal clearly contradicted the so-called "Brezhnev doctrine" used to justify, among other things, Warsaw Pact intervention in Czechoslovakia in 1968. Thus one can presume again that the USSR was not prepared to accept an agreement containing such provisions. In this they probably had at least the tacit support of other ruling Communist party governments in Eastern Europe and perhaps of some Western countries which also tend to view any civil war or other domestic instability as potentially undesirable sources of international instability.

On the fifth principle dealing with the "peaceful settlement of disputes," the Swiss delegation presented a lengthy proposal regarding the establishment of complex machinery for settling disputes in Europe. ${ }^{42}$ This proposal specifically dealt with the use of negotiations, conciliation, and arbitration for the settlement of

${ }^{40} \mathrm{CSCE}$ Document II/A/30/Rev. 1, 17 March 1975.

${ }^{41}$ CSCE Document II/A/1 14, 25 February 1974.

${ }^{42} \mathrm{CSCE}$ Document II/B/1. 
disputes. The proposal was opposed by several states, especially by the Soviet Union, and the Swiss were successful in obtaining only a commitment to have a meeting of experts to prepare a position on this issue to be presented to the 1977 review conference. Although in this case the veto was not absolute, it was sufficient to postpone the specific discussion of this issue. It was thus possible for the USSR and other opponents of this proposal to get a CSCE agreement which did not contain this provision, once again preventing a nonaligned proposal from being adopted.

The first part of the section on confidence-building measures dealt with the notification of any large scale military maneuvers held on the territory of all participants within Europe. Here there were some differences over the definition of a major maneuver, finally settled at a threshold of 25,000 troops; over the territory to be covered in the USSR which extends beyond Europe, settled at a distance of 250 kilometers from its border with any other participating European state; and the amount of time in advance that notification should be given, finally set at 21 days or more. All of these issues, however, were settled by compromise since these were questions on which it was relatively easy to proceed by "splitting the difference."

The issue of the exchange of observers at these maneuvers did create some divisions along "East-West" lines. The USSR contended that observers should be exchanged by "invitation" and "under mutually acceptable conditions." 43 On the other hand, the British proposed that each participating state "will invite each other on a bilateral basis to send observers. . ."44 Although both texts were similar, the Soviets emphasized the voluntariness of the invitation whereas the British emphasized its imperativeness. The result reflected a position suggested by six nonaligned nations: Austria, Cyprus, Finland, Sweden, Switzerland, and Yugoslavia, to make the invitation by each participating state "at its own discretion, as a sign of goodwill and with due regard to reciprocity. . ."45 Thus on this crucial issue the position of the Soviet Union tended to prevail, although the nonaligned nations suggested a compromise wording which made the proposal acceptable to the West.

The next issue on CBMs involved the notification of major military movements. Specific proposals calling for the required notification of all large-scale movements of force in Europe were presented by Great Britain ${ }^{46}$ and by the six nonaligned nations referred to earlier. ${ }^{47}$ These provisions were explicitly supported by Rumania, ${ }^{48}$ Yugoslavia, ${ }^{49}$ Norway, ${ }^{50}$ Belgium, ${ }^{51}$ and the Federal Republic of Germany. ${ }^{52}$ Although none of the Warsaw Pact nations commented on this proposal

${ }^{43} \mathrm{CSCE}$ Document II/C/1, 19 September 1973.

${ }^{44} \mathrm{CSCE}$ Document II/C/12, 4 February 1974.

${ }^{45} \mathrm{CSCE}$ Document II/C/13, 19 February 1974.

${ }^{46} \mathrm{CSCE}$ Document II/C/12, 4 February 1974.

${ }^{47} \mathrm{CSCE}$ Document 1//C/13, 19 February 1974.

${ }^{48} \mathrm{CSCE}$ Document II/C/2 21 September 1973.

${ }^{49} \mathrm{CSCE}$ Document II/C/3 24 September 1973.

${ }^{50} \mathrm{CSCE}$ Document II/C/4, 26 September 1973.

${ }^{51} \mathrm{CSCE}$ Document II/C/10, 7 December 1973.

${ }^{52}$ CSCE Document II/C/11, 21 January 1974. 
in writing except for Rumania, this provision was favored by virtually all participants in the CSCE except two, the United States and the Soviet Union. This is perhaps the most dramatic case in "basket one" of the CSCE of the appearance of the so-called "superpower condominium." Yet these two nations together were effectively able to reduce the provisions in the final document to a possibility of notification by participating states "at their own discretion" of major military movements. The document also calls for future discussion of this issue.

Several other measures proposed by nonaligned or subordinate bloc members were also effectively vetoed by one or both superpowers. For example, a Rumanian proposal calling for further concrete negotiations on disarmament and withdrawal of all foreign troops ${ }^{53}$ was reduced to a vague statement about the "necessity to take effective measures in these fields (disarmament and détente) which by their scope and by their nature constitute steps towards the ultimate achievement of general and complete disarmament under effective international control...." In recent years both superpowers have been increasingly reluctant to view plans for general and complete disarmament (GCD) as being either desirable or feasible in the near future. Rather they have favored a slow, piecemeal approach to disarmament. In spite of the reference to GCD in the text, the principle of the step-by-step approach favored by the two superpowers is clearly endorsed as opposed to the more immediate and sweeping proposals favored by Rumania. Similarly a Swedish proposal calling for the publication by all participating states of their detailed defense budgets ${ }^{54}$ was rejected largely due to the opposition of the USSR. Finally, a Yugoslav proposal for the gradual "elimination of foreign military forces stationed on the territory of the countries of Europe or on the Mediterranean ${ }^{\prime} 55$ met with strong opposition as well from the two superpowers.

This survey of decision making on several of the most widely contested issues appearing before the committees drafting the section on security in the CSCE indicates that a far greater degree of asymmetry was apparent in these negotiations than appeared in the analysis of the authorship of the final text. This is because the asymmetry in bargaining was not only reflected in what was put in the document but also in what was left out. Proposals made by the most active nonaligned states, especially Yugoslavia, Sweden, and Switzerland, were often either set aside or drastically watered down due to the objections of one or both of the superpowers. Even within the blocs there were indications that the proposals of the smaller nations were effectively vetoed by their larger allies on several occasions. This was evidenced by Soviet opposition to Rumanian proposals on the non-use of force for the settlement of disputes and in American opposition to the British proposals for a compulsory notification of major military movements.

In at least several respects, the two superpowers were both in an advantageous position in the CSCE. First, they were obviously the strongest actors in terms of both

\footnotetext{
${ }^{53} \mathrm{CSCE}$ Document 11/C/8, 28 September 1973.

${ }^{54} \mathrm{CSCE}$ Document II/C/9, 23 October 1973.

${ }^{55}$ CSCE Document II/C/3, 24 September 1973.
} 
economic and military resources and thus also the most capable of issuing credible threats and/or promises. Second, they also had the greatest threat potential since they would suffer fewer losses than most of the other nations from the failure to agree. Of course, both would have been hurt somewhat by nonagreement since this would have represented a break in the momentum of détente. But in terms of the content of the agreement itself, both also had something to lose since the major thrust of the CSCE was to reduce the bloc structure of political-military-economic interactions on the European continent. Along the same line the conference sought to establish the independence and sovereign equality of all nations. Thus insofar as the principles of the agreement were given any concrete content (which in fact they often were not), this might provide a greater limitation on the ability of the two superpowers to dominate their respective alliances and to intervene actively in European affairs. Furthermore, since any agreement without either or both of the superpowers would have been greatly weakened, any threat by either to opt for no agreement would have been viewed seriously by the other participants. Thus, since nonagreement would not have been terribly costly to the United States or to the Soviet Union and since no agreement or an agreement without the participation of the superpowers would have cost most of the other participants substantially in terms of their goals of enhancing their status and freedom of action in European affairs, the two bloc leaders, also endowed with predominant economic and military power, obtained substantial leverage over the outcome of the CSCE negotiations. In the case of the USSR this leverage was reflected both in a substantial contribution to the authorship of the final document (over 16 percent of the attributable text) and in a power of veto or postponement over many other proposals advanced by both nonaligned nations and by a rebellious ally, Rumania. For the United States the leverage was reflected more in bargaining within the NATO alliance to influence its general stance and in a power to veto or postpone some issues favored by nonaligned nations and by weaker allies.

Thus, the analysis of the authorship of the final text did not consistently show very substantial asymmetry. However, it did indicate that, with several important exceptions, nations with the least to lose from nonagreement in fact exerted greater influence on the text than those with more to lose. It also indicated that there was some relationship between military resources and influence over the portions of the text dealing with "confidence building measures."

However, the most significant sources of asymmetry appeared, not in influence over what was included in the final act of the CSCE, but over what was excluded from it. This power of veto was exercised most strongly by the two superpowers in the negotiations, the United States and the Soviet Union, indicating a strong degree of asymmetry based on "threat potential," on structural position within the international system, and on resources to back up influence attempts. Furthermore, some states which were actively involved in the negotiations and which proposed a large portion of the text, especially Yugoslavia, France, and Rumania, were not as influential overall as might be suggested by measures of their contribution to the final agreement. Their strong interest in an agreement led them to make a significant number of proposals. Since some of these were adopted, they were among the 
leading nations in terms of authorship of the text of the final act. However, a large number of their significant proposals were vetoed by the two superpowers. They were thus not as influential overall as might appear since many of their most important proposals did not appear in the final act. Therefore, the analysis of "non-decision-making" in the CSCE strongly supports the hypothesis about the effects of both differences in resources and in utilities assigned to nonagreement as important factors contributing to asymmetrical outcomes in negotiations.

The severe problems with operationalizing some of the most important variables suggested in the theoretical conceptualization limited significantly the conclusions that can be drawn from this study. However, the propositions presented in this paper were drawn from a general conceptualization of bargaining under conditions of structural asymmetry, based in part on formal game theory and a strategicmanipulative model of the bargaining process. The propositions are logically consistent with some fundamental assumptions of these bodies of theory. Furthermore, the propositions were generally found to be consistent with the negotiations which occurred in the Conference on Security and Cooperation in Europe with some exceptions. Of course, reality is always more complex than any simple model, and the results of this study indicate some important considerations that the model overlooks. Nevertheless, the negotiations on CSCE did demonstrate certain significant asymmetries in outcomes. These asymmetries seemed to reflect to a substantial degree both the relative "threat potential" and the relative resources of the nations participating in these negotiations, suggesting that these orientations need to be brought together in any adequate theory of bargaining under conditions of structural asymmetry. 